\title{
Cystic Lesion Growing Like Abscess Developing after Chronic Subdural Hematoma Drainage
}

\author{
Kronik Subdural Hematom Drenajı Sonrası Gelişen Apse Benzeri \\ Büyüyen Kistik Lezyon
}

\section{Tolga Turan DÜNDAR, Mehmet Hakan SEYITHANOĞLU, Serdar ÇEVIK, Fatih ÇALIŞ, Enes AKKAYA, Şevket EVRAN, Talha ŞIMIŞEK \\ Department of Neurosurgery, Bezmialem Vakif University, Faculty of Medicine, Istanbul, Turkey}

\section{ABSTRACT}

Chronic subdural hematoma and cranial abscess are two phenomena that are easy to differentiate in daily neurosurgical practice. Although the neurological symptoms may be the same in both, today's imaging techniques and laboratory facilities are helpful for a definitive diagnosis. In this study, a patient who was operated on for a subdural hematoma came to the emergency room after 1 month with distinct hemiparesis appearing in the right arm and speech difficulties. Hospitalized due to the appearance of an abscess, which had a pachys capsule, keeping the contrast in the left parietal in the cranial CT and MR, the patient was operated on, and the mass was excised, along with the capsule. The lesion of the patient, which showed no reproduction in the culture, was diagnosed as a growing hemorrhagic cystic lesion, covered by a thick capsule. The literature showed no such growing cystic lesion causing a shift like an abscess after chronic subdural hematoma operation. We believe that it would be appropriate to consider a differential diagnosis, besides diagnoses, such as abscess or subdural empyema. Do we evaluate cystic lesion like abscess such as inflammatory response.

Key Words: Hydrocephalus, subdural hematoma, intracerebral abscess, intracerebral cyst

\section{ÖZET}

Kronik subdural hematom ve kranial abse günlük nöroşirurji pratiğinde kolay ayırt edilebilen tanılardır. Her iki kranial patolojinin nörolojik semptomları aynı olabilmektedir. Günümüzün görüntüleme teknikleri ve laboratuar imkanları kesin tanı için yardımcıdır. Bu çalışmada Kronik Subdural Hematom (KSDH) nedeni ile opere olan hasta, bir ay sonra sağ kolda belirgin hemiparazi ve konuşma güçlüğü ile acil servisimize geldi. Kranial Bilgisayarlı Tomografide (BT) ve Magnetik Rezonans (MR) görüntülemede sol parietal lobda kontrast tutan kalın kapsüle sahip apse görünümü olması nedeni ile servise alındı. Daha sonra opere edilerek kapsülü ile birlikte kitle eksize edildi. Geniş spektrumlu antibiyoterapi başlandı. Hastanın ameliyat esnasında alınan materyal kültürlerinde üreme olmadı. Literatürde; kronik subdural hematom ameliyatı sonrası, apse benzeri görüntüye sahip, büyüyerek şifte neden olan kistik lezyona rastlanmadı.Apse ve/veya subdural ampiyem, KSDH lardan sonra görülebildiği gibi benzer görünümleri nonspesifik enflamasyon yanıtı olarak da değerlendirebiliriz. Bu çalışmada; geçirilen bir dizi kranial ameliyatlardan sonra,intrakranial abse benzeri lezyon ile başvuran hastanın sunumunu yapmayı amaçladık.

Anahtar Sözcükler: Hidrosefali, subdural hematom, intraserebral abse, intraserebral kist

\section{Giriş}

Non travmatik kronik subdural hematom ile günlük nöröşirurji pratiğinde sıklıkla karşılmaz. Non travmatik subdural hemorajiler koagulasyon bozukluklarına bağlı olabileceği gibi cerrahi sonrası (kraniotomi, VP shunt uygulaması gibi) veya intrakranial hipotansiyona neden olan girişimlerden sonrada (Lomber Ponksiyon, LP shunt,spinal epidural anestezi gibi) görülebilmektedir $(1,2)$.

Subdural ampiyem dura mater iç tabakası ile araknoid membran dış tabakası arasındaki potansiyel boşlukta pü birikmesi olarak tanımlanır. Subdural ampiyemin en sık nedeni çocuklarda menenjit, erişkinlerde ise otolaringeal enfeksiyonlardır. Daha önce geçirilen cerrahi ve travma ise diğer nedenleri oluşturur (3-6). 
Her ikisinin de nörolojik semptomları aynı olabilmekle beraber, günümüzün görüntüleme teknikleri ve laboratuar imkanları kesin tanı için yardımcıdır.

Bu çalışmada; geçirilen bir dizi kranial ameliyatlardan sonra, intrakranial abse benzeri lezyon ile başvuran hastanın sunumunu yapmayı amaçladık. Günümüzde subdural ampiyem tedavisinde burr-hole deranaj mı yoksa kranyotomi ile dekompresyon mu halen tartışılmaktadır. Literatürde; kronik subdural hematom ameliyatı sonrası, apse benzeri görüntüye sahip, büyüyerek şifte neden olan kistik lezyona rastlanmadı. Apse veya subdural ampiyem, KSDH lardan sonra görülebildiği gibi benzer görünümlerin nonspesifik enflamasyon yanıtı olarak da değerlendirelebilinir.

\section{Olgu Sunumu}

Acil servise ani başlayan sağ üst ekstremitede güç kaybı, baş ağrısı, konuşma bozukluğu nedeni ile başvuran, 21 yaşında bayan hasta. Fizik muanesinde; sağ üst ekstremitede pleji, sağ üst ekstremitede derin tendon reflekslerinde artma ve motor afazi tespit edildi. Ense sertliği mevcut değildi. Vücut sıcaklığıda dahil vital bulguları normal sınırlarda idi.

Özgeçmişinde; 2,5 yıl önce normal basınçlı hidrosefali nedeni ile sağ taraflı ventriküloperitoneal şant uygulanan hasta, 2 ay önce valv disfonksiyonu nedeni ile revizyon ameliyatı geçirmiş. Bu süre zarfında bir problem ile karşılaşılmamış. Revizyonun 1. ayında bilateral subdural efuzyon ile başvuran hastada nörolojik defisit saptanması üzerine burr hole ile drenaj sağlandı ve motor defisitde tam düzelme görüldü (Resim 1A). Bundan 15 gün sonra, sol burr hole insizyon trasesinde cilt enfeksiyonu nedeni ile debritman uygulanıp antibiyoterapi başlanıp, kontrol beyin BT si alındı (Resim1B).

Yara yeri sürüntü kültüründe stafilokokus epidermidis üreyen hastanın, son başvurusundan 5 gün önce antibiyotik tedavisi kesilip ve tekrar beyin BT çekildikten sonra iyilik hali görülmesi üzerine taburcu edildi (Resim 1C).

Daha sonra başağrısı ve uykuya eğilim nedeni ile acil servise başvuran hastanın kontrasız kranial BT sinde sol paryetalde $3 \times 3 \mathrm{~cm}$. ebatlarında hipodens alan mevcutdu. (Resim 1D) Orta hatta $1,5 \mathrm{~cm}$ şifti olup kontrastlı beyin BT sinde ise hipodens alanın çevresinde yoğun kontrast madde tutan kapsül vardı.(Resim 1E) Cilt enfeksiyonu öyküsü nedeni ile ön planda intraparankimal abse düşünüldü. Fakat difüzyon MR incelemesinde enfeksiyon lehine bulgu saptanmadı (Resim 1F).

Hastanın sedimentasyon ve beyaz küre ve CRP değerleri normaldi. Hastanın kan ve idrar kültürleri alındıktan sonra genel anestezi altında yaklaşık 90 cc efüzyon sıvısı aspire edildi. Pürülan değildi.Sıvı kültür ve mikrobiyolojik incelemeye gönderildi. 1-2 lökosit tespit edildi. Bakteri görülmedi. Ertesi gün erken dönem motor defisiti düzeldi fakat akşam saatlerinde nörolojik kötüleşme meydana gelen hastanın kontrol BT sinde efüzyon alanın tekrar dolduğu ve şifte yol açtığı gözlemlendi.
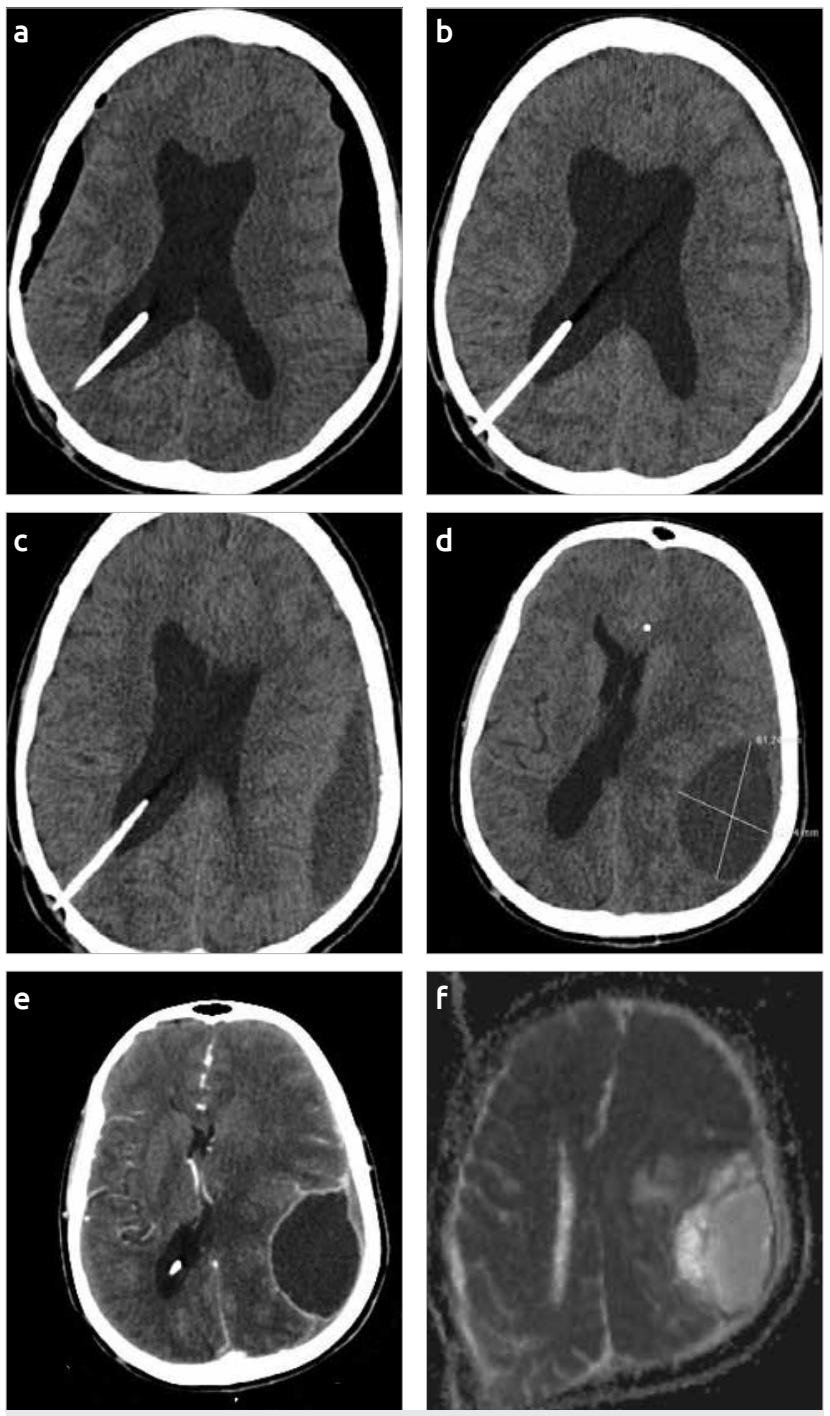

Figure 1. a-f. a. Subdural Efüzyon. Operasyon öncesi BT görüntülemesi, b. Subdural Efüzyon. Operasyon sonrası BT görüntülemesi, c. Subdural Efüzyon. Operasyon sonrası, hastaneden taburculuk öncesi kontrol BT görüntülemesi, d. Acil servis'te çekilen kontrasız kranial BT. Sol paryetalde $3 \times 3 \mathrm{~cm}$. ebatlarında hipodens alan, f. Acil servis'te çekilen kontraslı kranial BT. Sol paryetaldeki lezyonun yoğun kontrast tuttuğu görülmektedir, f. Difüzyon MR incelemesi

Sonrasında hastada dramatik nörolojik düzelme meydana geldi. Post op kranial MR' da kitlenin belirgin şekilde küçüldüğü ve shiftin kaybolduğu gözlendi(Resim 2B, 2C). Hastanın nörolojik tablosu tamamen düzeldi. Postoperatif 6 . ay beyin BT'sinde parankimal lezyona rastlanmadı (Resim 2D).

\section{Tartışma}

Hidrosefali tanısı alıp ameliyat gereksinimi olan hasta grubunda santral sinir sistemi enfeksiyonları sık görülmektedir. Bu durum tekrar yapılması gereken ameliyatları ortaya çıkarmaktadır (materyalin çıkarılması, değiştirilmesi gibi). Hasta ve hasta yakınlarının bu süreçler hakkında bilgilendirilip rızalarının alınması, takip ve tedaviye katkı sağlamaları açısından da tıbbi ve ahlaki bir zorunluluktur. Bizde vaka 

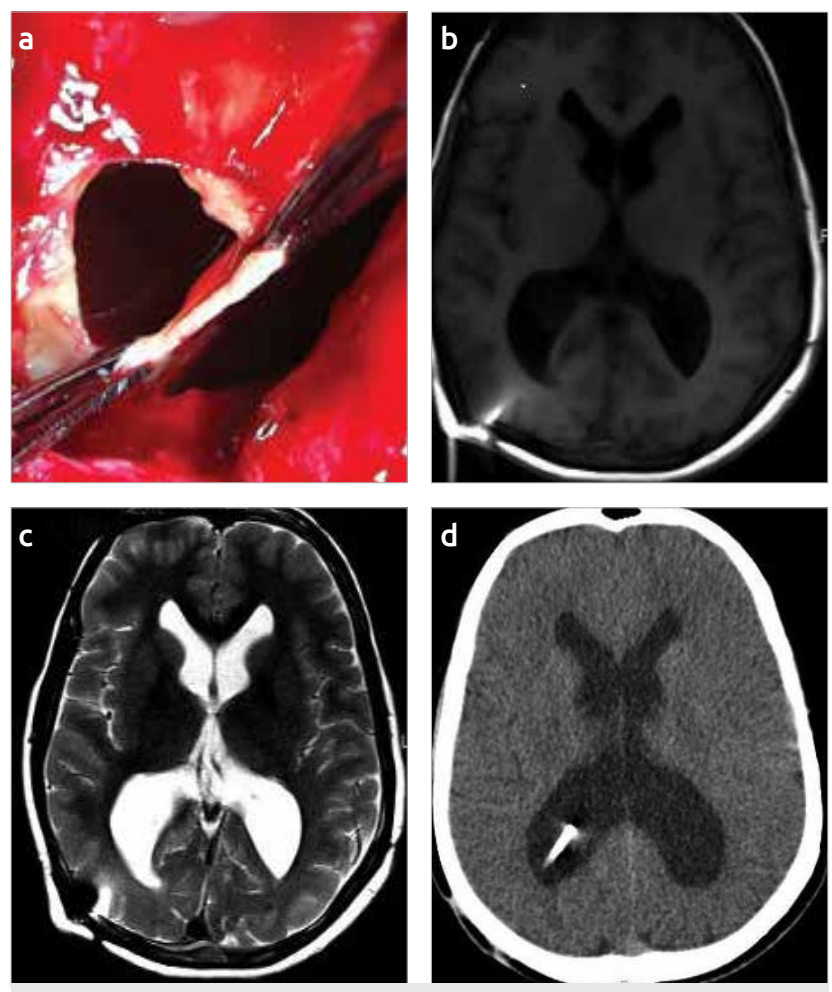

Figure 2. a-d. a. Operasyon sonrası BT görüntülemesi, b. Operasyon sonrası MR görüntülemesi, c. Operasyon sonrası MR görüntülemesi, d. Operasyon sonrası 6.ay kontrol BT'si

olarak takdim ettiğimiz hasta ve yakınlarına yapacağımız tüm işlemler hakkında bilgi verip, onamlarını da alıp tedavi sürecine aktif katkılarını sağladık.

Kronik Subdural Hematom Dura ve araknoid arasında vaskuler yapldan zengin dış membran ile, avaskuler iç membranın cevrelediği kan, fibrin ve fibrin yıkım ürünlerinin bulundugu bir koleksiyonu ifade eder (7-8). Lokal hiperfibrinolizis ile subdural kan pıhtısı erir, duranın ic yaprağıdaki sinuzzoidal damar lumenleri genişler ve KSDH'nin dış membranı oluşur. Endotelyel tabakanın yetersiz gelişmiş olması dolayısıyla yeni membranlar içindeki kan damaları aşırı geçirgenliğe sahip olması ilerleyici sıvı birikimine ve hematom içine tekrarlayıcı kanamalara neden olabilmektedir (9). Bu sıvı birikimi subdural hematomun boyutunu dolayısı ile kitle etkisini arttırıp nörolojik bulguların belirginleşmesine neden olabilir.

Serebral abse, akciğer anomalileri (enfeksiyon, A-V fistül vb.), konjenital siyanotik kalp hastalığı, bakterital endokardit, penetran kafa travması, kronik sinüzit, otitis media ve AIDS risk faktörleri arasında sayılabilir. Kan kültürleri genelde negatiftir. Periferik kanda beyaz küre normal veya olgıuların \%60-70'inde hafif yüksek olabilir. Eritrosit sedimentasyon hızı normal olabilir. Klinik semptomların hiç biri abse için özgül değildir ve bunların çoğu lezyonu çevreleyen ödeme bağlı olarak gelişir. Genellikle başağrısı, bulantı, kusma, letarji gibi KİBAS bulguları görülür. Hemiparezi ve nöbet görülme sıklığıda az değildir. Olguların \%25 ine yakın bir kısmında kaynak saptanamamıştır. 1980 öncesine kadar en sık komşuluk yoluyla yayılım serebral abseye neden olurken, günümüzde hematojen yayılım daha sık görülür. Bu şekilde görülen abselerin \% 10-50 si birden fazla sayıdadır (3-10).

Streptokok en sık rastlanan organizmadır. \%33-50'lik bir kısmı anaerob veya mikroaerofiliktir. Genellikle olguların \%10-30'unda kültürde birden fazla mikroorganizma üretilebilir ve bu oran bazı serilerde \%80-90'a çıkabilmektedir.

Suçlanan patojenler içinde Streptokok ensık rastlanan organizmadır. \%33-50'lik bir kısmı anaerob veya mikroaerofiliktir. Genellikle olguların \%10-30'unda kültürde birden fazla mikroorganizma üretilebilir ve bu oran bazı serilerde \%80-90'a çıkabilmektedir (3-11).

Subdural ampiyem 1943 öncesine kadar subdural abse olarak bilinirdi (3-12). Subdural ampiyem subdural mesafede oluşan ve yayılmasına engel olabilecek anatomik bir bariyer olmayan supuratif bir enfeksiyondur (13). Subdural ampiyemler tüm intrakranial enfeksiyonların \% 15-25'ini oluşturur (14-15). Görüntüleme çalışmalarında subdural ampiyem ve beyin absesi \%20-25 oranında birlikte görülmektedir.

Subdural ampiyemin en yaygın klinik triadı ateş, sinüzit ve nörolojik defisittir. Baş ağrısı, nöbet, iştahsızlık, bulantıkusma, komaya kadar giden şuur bozuklukları da görülebilir. Kafa içi basınç artışı bulguları da görülebilir. Semptomlar sıklıkla lezyonun kitle etkisine bağlıdır. Hemiparazi, ataksi, afazi gibi fokal nörolojik bulgular apsenin lokalizasyona bağlıdır (3-4).

Subdural ampiyem tanısı, kranial bilgisayarlı tomografi (BT) veya manyetik rezonans görüntüleme (MRG) ile konabilir (16). BT de yalancı negatiflik \% 30'lara kadar çıkabilir. Kontraslı incelemeler tanıda daha değerlidir. Kranial BT'de hemisferik bölgede hipodensite, çevre kortikal yapılarda ödem ve sulkuslarda silinme gözlenir (17). Kontrastlı kranial BT'de lezyonda, BOS’a göre hafif hiperdens çepersel boyanma gösterebilir. Difüzyon ağırlıklı görüntüleme gibi daha yeni MR görüntüleme yöntemleri MSS enfeksiyonlarına bağlı lezyonların değerlendirilmesinde konvansiyonel MR görüntülemeye göre daha fazla ek bilgi sağlayabilmektedir. Özellikle etkilenen alanların erkenden belirlenmesinde yararlıdır ve hastalık evresinin belirlenmesine katkıda bulunabilir (18-19).

Sunulan vakada, hasta daha önce ara ara başağrısı şikayeti ile polikliniğimize başvurmuş, çekilen kontrol BT lerinde rezidü subdural efüzyonun çok fazla rezorbe olmadığı hatta kistik yapı şeklinde sınırlandırılması ve kapsülasyon aşamaları dikkati çekti (Resim 1A, 1B, 1C). Beyin parankimin bu yanıtı mevcut patolojiyi sınırlama çabası olarak algılanabilinir. Apseye benzeyen bu formasyon kliniğimiz subdural hematom nedeni ile takip ettiğimiz hastalar içinde ilk defa görülmüş idi. Kistik lezyonun peroperatif görünümünün $1-1.5 \mathrm{~cm}$ lik kapsülasyonun beyin yüzeyine doğru ilerlediği ve büyüyen kistik yapıyı sınırladığı görüldü . Kistin büyümesi kapsülden muhtemel sekresyon olabileceğini düşündürttü. Mevcut ven- 
triküloperitoneal şantın kistik kavite oluşumunda etkisinin olup olmadığı noktasında litaratürde yeterli bilgi bulunamadı.

Kronik subdural hematom ve subdural ampiyem gerek predispozan faktörler gerek görüntüleme yöntemleri ile preop kolayca ayırt edilir.

Fakat presente ettiğimiz vaka gibi predispozan faktörler ve görüntüleme yöntemleri preop ayırt etmekte yardımcı olmayabilir. Difüzyon ağırlıklı görüntüleme, konvansiyonel MR görüntülemeye göre daha fazla ek bilgi sağlamasına rağmen kranial ve spinal enfeksiyon hastalıklarındaki rolü araştırılmaktadır (18-19). Bizim vakamızda da kontraslı incelemer enfeksiyon lehine iken difüzyon ağırlıklı MR incelemesinde enfeksiyon lehine bulgu yokdu.

\section{Sonuç}

Tüm gelişmiş görüntüleme ve laboratuvar tetkiklerine rağmen bazı intrakranial hadiselerde kesin tanı koymak zordur. İleri radyolojik tetkiklerinde yanlış negatif sonuçlar verebildiği unutulmamalıdır. Kronik subdural effüzyon drenajı sonrası gelişen kistik kapsüle lezyonun ayırıcı tanısında subdural ampiyem ve serebral apseler düşünülebilir. V-P şant kist oluşumuna sebep olabilir. Bu lezyonların tedavisinde drenajla basit dekompresyon yetersiz kalmakta mutlaka kapsül eksizyonuda gerekmektedir.

Informed Consent: Written informed consent was obtained from the patient who participated in this case.

Peer-review: Externally peer-reviewed.

Author Contributions: Concept - T.T.D.; Design - T.T.D.; Supervision - M.H.S.; Data Collection and/or Processing - S.Ç., F.Ç., E.A., Ş.E., T.Ş.; Analysis and/or Interpretation - M.H.S.; Literature Review - T.T.D.; Writing - T.T.D

Conflict of Interest: No conflict of interest was declared by the authors.

Financial Disclosure: The authors declared that this case has received no financial support.

Hasta Onamı: Yazılı hasta onamı bu olguya katılan hastadan alınmıştır.

Hakem Değerlendirmesi: Dış bağımsız.

Yazar Katkıları: Fikir - T.T.D.; Tasarım - T.T.D.; Denetleme - M.H.S.; Veri Toplanması ve/veya İslemesi - S.Ç., F.Ç., E.A., Ş.E., T.Ş.; Analiz ve/veya Yorum - M.H.S. ; Literatür Taraması - T.T.D. ; Yazıyı Yazan - T.T.D.

Çıkar Çatışması: Yazarlar çıkar çatışması bildirmemişlerdir.

Finansal Destek: Yazarlar bu olgu için finansal destek almadıklarını beyan etmişlerdir.

\section{References}

1. Pérez-Guerra. Chronic subdural hematomas, J Med Archives Vol 19:2 2003

2. Mashour GA, Schwamm LH, Leffert L. Intracranial subdural hematomas and cerebral herniation after labor epidural with no evidence of dural puncture. Anesthesiology 2006; 104: 610-2. [CrossRef]

3. Greeberg MS. Beyin Absesi. Nöroşirurji El Kitabı. İstanbul. Güneș Tip Kitabevi. S:223-6, 2010.

4. Kaplan T, Kuytu T, Taşkapılıŏlu MÖ, Kocaeli H, Korfalı E, Bekar A. Subdural Ampiyemlerin 20 Yıllık Retrospektif Analizi (the retrospectif analyse of subdural amphyema for last twenty years) Uludağ Üniversitesi Tip Fakültesi J 2010; 36: 61-3.

5. Tummala RP, Chu RM, Hall WA. Subdural empyema in children. Neurosurgery quarterly 2004; 14: 257-65. [CrossRef]

6. Tsai YD, Chang WN, Shen CC. Intracranial suppuration. A clinical comparison of subdural empyemas and epidural abscesses. Surg Neurol 2003; 59: 191-6. [CrossRef]

7. Markwalder TM. Chronic subdural hematomas: A Review. Neurosurg 1981; 54: 637-64. [CrossRef]

8. Soylu U, Beşkonaklı E, Caylı S, Bostancı U, Yalçınlar Y. Kronik Subdural Hematomlar (Chronic Subdural Hematoma) Türk Noroşiruji Dergisi (Journal of Turkish Neurosurgery) 1995; 5: 70-2.

9. Kumar V, Cotran RS, Robbins SL. Robbins Basic Pathology 7th edition İstanbul. Nobel Tip Kitabevi 2003; 23: 819.

10. Mamelak AN, Mampalam TJ, Obana WG, Rosenblum ML.Improved management of multible brain abscesses. A combined surgical and medical approach. Neurosurgery 1985; 36: 76-86. [CrossRef]

11. Tezel K, Yılmaz N, Akbay FY, Aslantürk Y, Bostancı U, Taşkın Y. İntrakranial abselerde cerrahi tedavi sonuçları. Tıp Araştırmaları Dergisi (TAD) 2006: 4: 1-4.

12. Stephanov $S$, Sidani $A H$, Intracranial subdural empyema and its management. A review of the litarature with comment. Swiss Surg 2002; 8: 159-163. [CrossRef]

13. Kubik CS, Adams RD. Subdural Empyema. Brain 1943; 66: 18-42. [CrossRef]

14. Bok AP, Peter JC. Subdural empyema. Burr hole or craniotomy? A retrospective computed tomography era analysis of treatment in 90 cases. J Neurosurg 1993; 78: 574 8. [CrossRef]

15. Yılmaz N, Kiymaz N, Yılmaz C, Yuca SA, Mumcu C, Caksen H. Surgical treatment outcome of subdural empyema: A clinical study. Pediatr Neurosurg 2006; 42: 293-8. [CrossRef]

16. Younis RT, Anond VK, Davidson B. The role of computed tomography and magnetic resonance imaging in patients with sinusitis with complications, Laryngoscope 2002; 112: 224-29. [CrossRef]

17. Moseley IF, Kendall BE. Radiology of intracranial empyemas with special reference to computed tomography. Neuroradiology 1984; 26: 333-45. [CrossRef]

18. Mueller-Mang C, Castillo M, Mang TG. Fungal versus bacterial brain abscesses: is diffusion-weighted MR imaging a useful tool in the differential diagnosis? Neuroradiology 2007; 49: 651657. [CrossRef]

19. Lee EJ, Ahn KJ, Ha YS. Unusual findings in cerebral abscess: report of two cases. Br J Radiol 2006; 79: 156 161. [CrossRef] 